\title{
PRÁTICAS COTIDIANAS E SABERES POPULARES Reflexões teórico-metodológicas para o estudo da história das cidades
}

\author{
EVERYDAY PRACTICES AND POPULAR KNOWLEDGE \\ Theoretical-methodological reflections for the study of the \\ history of cities
}

\author{
A. Giovana Cruz Alves \\ Universidade Federal Fluminense, Brasil \\ giovanacruzalves@gmail.com
}

\begin{abstract}
RESUMO
Diante do crescimento e da consolidação do campo de pesquisas sobre história das cidades no Brasil, no âmbito da Arquitetura e do Urbanismo, o presente trabalho propõe uma reflexão sobre as possibilidades teóricas e metodológicas para o aprofundamento crítico desses estudos. Compreendemos a cidade como um espaço produzido material e simbolicamente pelo conjunto da sociedade urbana, a partir de uma complexa e plural rede de saberes. Por essa razão, consideramos a necessidade de contemplar nessas investigações, além dos aspectos morfológicos e técnicos priorizados pelo saber acadêmico, as subjetividades e contradições que envolvem as práticas e os saberes populares dos múltiplos sujeitos urbanos, que criam e transformam cotidianamente o espaço urbano. O comprometimento com a pluralidade de práticas, saberes e sujeitos tem como perspectiva o alargamento do nosso entendimento sobre as cidades brasileiras e a ampliação das possibilidades para o seu presente e o seu futuro.
\end{abstract}

Palavras-chave: cidade, história, práticas cotidianas, saberes populares.

Linha de Investigação: 1 . Cidade e projeto.

Tópico: História urbana e história do urbanismo.

\section{ABSTRACT}

Considering the growth and consolidation of the research field on the history of cities in Brazil, in scope of Architecture and Urbanism, this paper proposes a reflection on the theoretical and methodological possibilities for the critical deepening of these studies. We understand the city as a space produced materially and symbolically by the entire urban society, from a complex and plural network of knowledge. For this reason, we consider the need to contemplate in these investigations, in addition to the morphological and the technical aspects prioritized by academic knowledge, the subjectivities and contradictions that involve the practices and popular knowledge of the multiple urban subjects, who create and transform the urban space in their everyday lifes. The commitment to the plurality of practices, knowledge and subjects aims to broaden our understanding about Brazilian cities and expand the possibilities for their present and their future. 


\section{SÃOPAULO15 $17 \cdot$ LISBOA $25 \sim 26$ JUN 2020}

Keywords: city, history, everyday life practices, popular knowledge.

Research line: 1 . City and project.

Topic: Urban History and History of Urbanism.

\section{A história das cidades no campo da Arquitetura e do Urbanismo}

A prática de estudar a história das cidades tem sido algo comum a diversas áreas do conhecimento, especialmente a partir do século XIX, quando os desdobramentos dos processos de industrialização ocorridos em diversos países colocaram o fenômeno urbano no centro das reflexões teóricas e práticas do homem. Hoje, no campo da Arquitetura e do Urbanismo, o estudo da história das cidades e o acompanhamento das suas transformações constituem uma base importante para o aprofundamento das reflexões sobre o tema e, consequentemente, para o desenvolvimento de futuros projetos e planos que visam solucionar problemas e possibilitar melhores práticas de gestão do espaço urbano. Apesar do caráter essencialmente propositivo, típico do ofício de arquitetos e urbanistas, e, portanto, do inerente predomínio, nesse fazer, de um pensamento dirigido ao futuro, é possível dizer que, cada vez mais, o estudo da história das cidades tem ocupado significativos espaços nas investigações desse campo. O crescimento das pesquisas históricas no âmbito da Arquitetura e do Urbanismo ao longo das últimas décadas aponta, assim, para a necessidade de refletirmos sobre as teorias e métodos que têm permeado essa esfera.

No âmbito brasileiro, a produção acadêmica de arquitetos e urbanistas sobre a história das cidades ganhou corpo no final da década de 1980. Segundo os arquitetos e urbanistas A. Fernandes e M. A. Gomes (2004), que realizaram importante mapeamento e análise das pesquisas realizadas por seu pares nesse campo histórico entre 1989 e 2001, é possível observar que, naquele período, descortinou-se um novo panorama em relação aos focos de interesse, que passaram a se deslocar da habitação para a cidade. De acordo com eles,

De um lado, isto parece decorrer da própria evolução do estudo da questão habitacional e, de outro, parece estar associado ao desenvolvimento dos estudos de história social em um momento de distensão política, com consequente aumento da problematização da história do movimento operário. (Fernandes; Gomes, 2004: 23)

Em meio àquele cenário político e a partir das importantes contribuições decorrentes do debate da história social, configurou-se um redirecionamento de perspectiva por parte dos arquitetos e urbanistas pesquisadores da história das cidades, deixando transparecer um menor interesse em abordar a sua forma e uma maior preocupação com as questões sociais inerentes ao contexto urbano. A análise realizada por Fernandes e Gomes (2004) também apontou algumas tendências que começaram a se apresentar de forma inovadora naquele momento, dentre as quais vale destacar: o distanciamento das investigações em relação às periodizações tradicionais da história, geralmente ancoradas nos aspectos políticos ou econômicos da história do país; a inclusão de outras categorias sociais, que não as elites, como produtoras de história e de memória; a sensibilidade aos eventos singulares como enriquecedores das problemáticas urbanas; a atenção às transformações no próprio campo disciplinar do urbanismo e às atuações dos profissionais da área.

Tendências semelhantes foram observadas em outra pesquisa, que empreendeu o esforço de mapear e analisar alguns trabalhos sobre a cidade e sua história desenvolvidos tanto por arquitetos e urbanistas 


\section{SÃO PAULO15 17 LISBOA $25 \sim 26$ JUN 2020

quanto por historiadores, entre as décadas de 1960 e 1990. No plano das pesquisas desenvolvidas pelos arquitetos e urbanistas, as historiadoras M. Carpintéro e J. Cerasoli (2009) observaram uma grande diversidade quanto às concepções de história utilizadas como recurso, o que, segundo elas, conferiu características distintas a esse conjunto de estudos. Uma parte deles ancorava a compreensão da cidade, sua morfologia e sua arquitetura em determinadas análises econômicas, políticas ou sociais da história, de modo que estas eram trazidas como responsáveis por explicar os fatos urbanísticos. Essa perspectiva coincide com uma noção de história entendida como uma sequência linear de acontecimentos ou como uma evolução natural deles, aparentemente sem conflitos. Outra parte transmitia uma leitura mais crítica dos pesquisadores, à qual as autoras se referem como sendo fruto de uma postura de suspeita, confronto e diálogo diante das fontes de pesquisa e dos dados encontrados. Nesse caso, os estudos revelavam uma interpretação da história mais dissociada das categorias dominantes e mais comprometida com as lutas sociais urbanas, trazendo à tona a percepção dos tensionamentos entre diferentes setores da sociedade. Havia ainda os que propunham reflexões sobre a história das cidades e as questões urbanas a partir de temáticas como a modernização social e a chamada "ideia sanitária", as quais estiveram presentes nos projetos urbanísticos e arquitetônicos das cidades ao longo dos séculos XIX e XX. E uma última parcela lançava uma perspectiva historiográfica sobre a trajetória teórica e prática da formação e da atuação dos próprios profissionais que operaram no planejamento e na construção das cidades brasileiras ao longo do século XX, tanto no âmbito privado quanto na administração pública.

O painel apresentado por Carpintéro e Cerasoli revela pontos em comum com a pesquisa de Fernandes e Gomes e indica, de forma ainda mais clara, por contemplar estudos anteriores à década de 1980, que aquelas tendências observadas nas pesquisas do fim do século eram, de fato, o pontapé inicial de um redirecionamento no campo. As novas perspectivas estavam sendo ainda inauguradas nos estudos históricos urbanos desenvolvidos por arquitetos e urbanistas, assim como estava sendo inaugurado o que podemos entender como uma bifurcação desse campo de pesquisa, que passava a se dedicar também à história do urbanismo enquanto disciplina. Tendo apresentado uma abordagem mais detalhada acerca das fontes utilizadas nos estudos analisados, a pesquisa de Carpintéro e Cerasoli ainda permitiu observar que, apesar da abertura a abordagens mais críticas, abrangentes e inovadoras, com exceção de um ou outro estudo que levava em consideração a memória de moradores para a construção do discurso histórico, a grande maioria das pesquisas ainda favorecia a difusão dos pontos de vista de agentes dominantes na produção do espaço urbano, ou seja, de sujeitos "notáveis", dotados de um conhecimento técnico ou entendidos como intelectualmente privilegiados: políticos, administradores públicos, viajantes estrangeiros, arquitetos, urbanistas, engenheiros sanitaristas, médicos higienistas. Isso porque essas investigações baseavam-se, quase sempre, em documentos produzidos por tais agentes e sujeitos: relatórios de dirigentes públicos e/ou técnicos especializados, relatos de viajantes, leis e decretos, mapas, planos e projetos, artigos e matérias de jornais e revistas, fotografias públicas e jornalísticas. Ou seja, em termos metodológicos, os estudos ainda preservavam antigos procedimentos e práticas naquele alvorecer do século XXI.

Vale destacar que, quanto às pesquisas de história urbana desenvolvidas pelos historiadores, Carpintéro e Cerasoli manifestam uma inquietação diante da constatação de que a presença da cidade, nesses estudos, colocava-se quase sempre de forma indireta e oblíqua, indicando um desvio de abordagem em relação à materialidade urbana e um predomínio do seu tratamento "apenas como palco das transformações políticas e econômicas, ou então, como cenário para os grandes acontecimentos sociais." (2009: 64) Nesse sentido, as autoras atentam para o risco de continuar privando a cidade de sua materialidade nesses estudos históricos e reivindicam as contribuições entre os diversos campos conceituais e disciplinares que envolvem 


\section{SÃO PAULO15 17 LISBOA $25 \sim 26$ JUN 2020

a temática urbana para uma "abordagem histórica da cidade que possa ansiar o alcance dessa complexa pluralidade de saberes e dimensões." (2009: 101)

Em um sentido semelhante, o trabalho do arquiteto e urbanista R. Faria (2015) também conclui sobre a importância da interdisciplinaridade para a contínua construção do campo da história urbana no âmbito da Arquitetura e do Urbanismo, após realizar uma espécie de atualização do balanço feito por Fernandes e Gomes na virada do século. O autor aponta uma consolidação do campo, após constatar alguns avanços obtidos no primeiro período do século XXI: a maior abrangência do conjunto de cidades contempladas nas investigações, assim como do conjunto de profissionais e planos urbanísticos pesquisados; a ampliação do escopo analítico das cidades brasileiras; a abertura para análises comparadas e articuladas com outros países e continentes. Segundo ele, no entanto, ainda existe uma necessidade de empreendermos novos esforços para o fortalecimento de uma perspectiva mais crítica da história da cidade. Nesse sentido, o autor questiona como poderíamos escapar de uma história urbana que seja reduzida à história da urbanização, pautada exclusivamente na materialidade, na técnica e no ofício dos arquitetos e urbanistas, e alcançar a densidade histórica da cidade, considerando, também, o seu tecido social com suas interações no ambiente urbano, suas subjetividades e contradições.

Vemos que, apesar dos grandes avanços no campo, ainda estamos diante de um caminho a ser percorrido rumo ao aprofundamento crítico das investigações sobre a história das cidades. Um aprofundamento que dê conta de associar a materialidade do tecido urbano e a subjetividade do tecido social, assim como de contemplar com maior profundidade o caráter plural dos agentes produtores do espaço urbano e os dissensos contidos na dinâmica da transformação urbana ao longo do tempo. Há, ainda hoje, um predomínio da macro ideia de que a história tem uma direção única, previamente conhecida, determinada pelo progresso e pelo desenvolvimento, o que acaba por colocar uma pequena seleção de saberes e sujeitos à frente da construção das narrativas históricas, como se esses ditassem, a partir de uma posição hegemônica, o rumo da própria história. (Santos, 2002) No contexto brasileiro, é possível dizer que essas noções de progresso e desenvolvimento estão contidas na colonialidade do nosso saber, um fenômeno que nos leva, ainda hoje, à reproduzir a falsa ideia de que somos atrasados em relação a outros países e, consequentemente, à reincidir na produção de um duplo processo de apagamento e inculcação de conhecimentos, conceitos, valores e visões de mundo. Sob essa ótica hierárquica, instituída no início da modernidade por meio do processo de colonização, ainda são criadas nas histórias das nossas cidades as ausências de uma série de saberes e sujeitos, os quais, em uma complexa rede, também produzem cotidianamente a cidade, seja simbolicamente, por meio do uso e apropriação dos espaços planejados pelos atores hegemônicos da disciplina urbana, seja materialmente, pela construção efetiva de espaços alternativos diante da impossibilidade de acesso aos espaços ditos "formais".

Nesse sentido, nos propomos aqui a uma reflexão acerca das possibilidades teóricas e metodológicas que venham a sugerir novas práticas de apreensão da cidade e da sua história, orientando, desse modo, uma produção historiográfica que preencha as lacunas existentes nesse campo de pesquisa da Arquitetura e do Urbanismo. É importante observar que as narrativas históricas vão, ao longo do tempo, consolidando um determinado modo de ver e abordar a cidade, sedimentando, assim, conceitos que acabam por influenciar as atuais práticas de planejamento e projeto urbanos e, consequentemente, o futuro das cidades. Como nos lembra Fontana (1998: 279), citando G. Orwell, "'quem controla o passado, controla o futuro e quem controla o presente controla o passado.' Isso explica a necessidade de dominar a história, ou seja, a memória coletiva." A observação do historiador catalão nos alerta sobre a relevância dos estudos históricos da cidade 


\section{SÃOPAULO15 17 LISBOA $25 \sim 26$ JUN 2020

e sobre a importância de uma postura acurada dos pesquisadores em relação à escolha das teorias e dos métodos que orientam as investigações, tendo em vista que os discursos estabelecidos a partir destas, em um duplo movimento de visibilidade e ocultação, são responsáveis por constituir as memórias da cidade e as bases conceituais para o seu presente e o seu futuro.

\section{Uma aproximação da cidade real}

A desconstrução de uma visão técnica, determinista e hegemônica da história das cidades e o incentivo ao desenvolvimento de um maior número de estudos que abranjam as múltiplas dimensões da produção do espaço urbano, considerando suas objetividades e subjetividades, seus conflitos e tensões, assim como os seus diversos atores, implicam uma mudança das lentes através das quais temos - arquitetos e urbanistas brasileiros - observado nossas cidades. Mais do que isso, implicam um reposicionamento do nosso ponto de vista, deslocando o olhar desde um lugar acima, distante e "privilegiado", de onde costumeiramente analisamos e planejamos as cidades, a um lugar no "interior" delas, onde as habitamos e onde se constitui o espaço vivido.

Como já citamos anteriormente, desde que foi inserido no contexto brasileiro nos anos 1980, o debate da história social tem trazido contribuições importantes para as pesquisas em Arquitetura e Urbanismo. Os intelectuais que se colocaram inicialmente nesse campo de pesquisa apresentaram uma crítica que sugeria não somente uma nova amplitude em relação aos temas que poderiam ser abordados nas pesquisas históricas, mas também um novo enquadramento das investigações, que deveria se deslocar para uma perspectiva que priorizasse as práticas e as experiências dos sujeitos e desse uma maior atenção, ainda, à existência de uma multiplicidade de sujeitos. E. P. Thompson (1981) defendia a ideia de que a história é dotada de uma lógica que é própria dos fenômenos que estão sempre em movimento e que evidenciam, assim, manifestações contraditórias. Em sua tese sobre a lógica histórica, Thompson demonstra que essa particularidade da ciência histórica a impede de furtar-se da subjetividade e lhe solicita uma posição de valorização da práxis, da ação humana e da experiência dos sujeitos históricos, uma posição, portanto, comprometida com o mundo real. Para o autor, tal comprometimento faria com que a base do trabalho do historiador fosse constituída por uma coleção de fatos e acontecimentos, a qual indicaria o caminho teóricometodológico a ser tomado. Nesse sentido, podemos dizer que as formulações de Thompson e de outros intelectuais da história social têm contribuído com um processo de recomposição do nosso objeto de pesquisa - a cidade - no interior do movimento social dinâmico no qual ele se constitui, apontando para a compreensão do conhecimento histórico da cidade como algo passível de contradições e sempre provisório.

Ora, a cidade real não é um organismo ordenado, normatizado, racionalizado, como nos parece enquanto a tratamos de modo distanciado, como ocorre frequentemente na esfera do planejamento e do projeto. A cidade real, vivida, é um espaço rasurado, cheio de desordens, tensões, contradições, apropriações. Um espaço sempre em transformação, criado, vivido, afetado e modificado continuamente pelos distintos sujeitos sociais que nele vivem e que com ele compõem uma realidade social urbana.

A respeito dessa condição inconstante e contraditória da cidade, H. Lefebvre (2011) também nos lembra que, uma vez modelado pelos processos globais, o espaço urbano admite que indivíduos e grupos ali se introduzam, se apropriem e constituam, por meio de seus atos e dos acontecimentos, o que ele chama de "relações de imediaticidade (ligadas a uma maneira de viver, de habitar, de modular o cotidiano)" (2011: 65, $66)$, produzindo, portanto, a realidade urbana. Segundo ele, a totalidade da dimensão urbana só se dá a 


\section{SÃO PAULO15 17 LISBOA $25 \sim 26$ JUN 2020

partir desse segundo processo, entendendo, assim, que "a cidade e a realidade urbana dependem do valor de uso." (2011: 14, grifo nosso) Isso implica que o estudo da história da cidade opere no plano da vivência e com métodos de apreensão capazes de capturar tanto o seu tecido material quanto o seu tecido social e as experiências que os constituem.

Formulações teóricas mais recentes, elaboradas no bojo dos estudos pós-coloniais e decoloniais, também têm contribuído para uma nova formatação do conhecimento social e urbano e evidenciado a crise das ideias de totalidade e progresso, as quais delimitaram o sentido e a direção da história e produziram, no interior do projeto euromoderno, o apagamento de uma diversidade de sujeitos, experiências e saberes que existem no mundo real, mas que não são reconhecidos pelo modelo hegemônico de racionalidade ocidental. A respeito disso, Boaventura de S. Santos (2002) afirma que alguns dos aspectos mais marcantes da racionalidade ocidental são a produção de não existências das formas sociais que escapam às suas delimitações, e o consequente desperdício de uma pluralidade de experiências compreendidas como residuais e inferiores, sendo portanto, não existentes. Sobre isso, é importante lembrar que o modelo de racionalidade ocidental orientou a construção material e simbólica de inúmeras cidades em territórios dominados pelas relações coloniais, como é o caso do Brasil. No entanto, segundo Santos, as lógicas da razão hegemônica ocidental nunca impediram a manifestação das outras formas sociais, apenas as desqualificaram a fim de mantê-las na relação de subalternidade. Nesse sentido, o autor reivindica a recuperação dessas experiências desperdiçadas e a transformação do olhar sobre elas.

Em sua crítica à racionalidade ocidental, Santos salienta que tal recuperação das experiências só será possível a partir de um novo modelo de racionalidade que seja capaz de compreender o mundo para além dos limites impostos pela compreensão ocidental do mundo. Ele afirma que "a característica mais fundamental da concepção ocidental de racionalidade é o facto de, por um lado, contrair o presente e, por outro, expandir o futuro." (Santos, 2002: 239) Ou seja, o presente é colocado como o instante fugidio; e o future, como algo indefinidamente expandido pela concepção linear do tempo. Nesse sentido, Santos propõe uma racionalidade que opere inversamente. Para expandir o presente, ele imagina uma sociologia das ausências, a fim de "revelar a diversidade e multiplicidade das práticas sociais e credibilizar esse conjunto por contraposição à credibilidade exclusivista das práticas hegemônicas." (Santos, 2002: 253) Uma sociologia que supere as totalidades homogêneas e excludentes, ampliando, assim, o próprio mundo. E, para contrair o futuro, uma sociologia das emergências, capaz de substituir o futuro vazio linear por um futuro de possibilidades plurais, constituídas no presente.

Nos termos das reflexões aqui construídas a partir das contribuições de Thompson, Lefebvre e Santos, mudar as lentes nos nossos estudos de história da cidade significaria, então, estabelecer uma reconfiguração epistemológica a partir da qual seja possível pensá-la e estudá-la não só com base no saber técnico e na racionalidade ocidental, aos quais o nosso conhecimento acadêmico está historicamente vinculado, mas com a incorporação de saberes e racionalidades outras. Significaria transformar e descolonizar o nosso conhecimento para, assim, ver as invisibilidades, ouvir os silenciamentos, dar forma às informalidades e transformar, portanto, as ausências em presenças. Já o nosso reposicionamento enquanto pesquisadores implicaria operar no plano da vivência, no cotidiano da realidade urbana - trabalhar no território, aprofundar o conhecimento acerca das práticas, apropriações e resistências que continuamente criam e modificam espaços e espacialidades e, é claro, dialogar com os múltiplos sujeitos e grupos sociais comumente marginalizados e subalternizados, trazendo-os para o centro da construção do conhecimento histórico com 


\section{SÃO PAULO15 17 LISBOA $25 \sim 26$ JUN 2020

suas dinâmicas cotidianas, suas práticas e lutas. Façamos, então, a partir dessas ideias, alguns apontamentos acerca do cotidiano urbano e das dinâmicas plurais que o compõem.

\section{Cotidiano, práticas e saberes populares urbanos}

Os estudos do cotidiano tiveram lugar no último terço do século $\mathrm{XX}$, quando as grandes transformações globais daquele período deram origem a uma série de alterações culturais e comportamentais, causando, assim, diversos questionamentos no âmbito das ciências sociais. Estudiosos de várias áreas se debruçaram sobre o tema do cotidiano na expectativa de que, nesse âmbito, poderiam ser desvelados diferentes significados e dimensões da realidade, o que permitiria trazer respostas para o planejamento de ações transformadoras capazes de contrapor a tendência que então se apresentava - a de uma homogeneização cultural e comportamental empobrecedora e limitada. Inseridas no contexto de suas pesquisas acerca da cultura, as contribuições de $\mathrm{M}$. de Certeau para a elaboração da noção de cotidiano apontaram para a definição de uma dimensão dotada de grande potencial inventivo e por meio da qual poderiam ser resgatadas as ideias do possível, do plural e do heterogêneo. Assim, o cotidiano, em Certeau (1998), admite a ideia da potencialidade para ações criativas, sendo a dimensão na qual, aos indivíduos e grupos, é afirmada a possibilidade das práticas desviantes, aquelas que, apesar de muitas vezes dispersas, silenciosas, anônimas e opacas, expressam distintos modos de fazer, mesmo a partir dos produtos estabelecidos e oferecidos pelas ordens dominantes.

Nessa concepção do cotidiano desenvolvida por Certeau, os produtos apresentados pelas ordens reinantes serviriam de suporte para outras produções e criações, constituindo-se, assim, uma lógica semelhante àquela existente em torno da noção de regra, a qual, concebida para impor limites, pode, paradoxalmente, estimular transgressões, improvisações e invenções. Há aqui, então, um entendimento de que os sujeitos sociais operam uma produção criativa autônoma e própria, por meio de suas práticas cotidianas de apropriação e manipulação daquilo que foi fabricado na esfera tecnocrática pelos chamados "produtores de cultura". Assim sendo, as maneiras de utilizar ou consumir os espaços e produtos culturais em universos pequenos e cotidianos constituem processos ativos e criativos daqueles a quem Certeau chama de praticantes ordinários. Trata-se de fazeres que escapam à disciplina, esboçando necessidades, interesses e desejos outros e revelando inventividades táticas e astutas, associadas a saberes de naturezas diversas.

"Habitar, circular, falar, ler, ir às compras ou cozinhar, todas essas atividades parecem corresponder às características das astúcias e das surpresas táticas." (Certeau, 1998: 103, 104) São ações múltiplas, de indivíduos marginais e heterogêneos que se manifestam dia após dia nas frestas do sistema instituído, transformando-o de acordo com as possibilidades e os elementos disponíveis em determinados instantes e condições. "Mil maneiras de jogar/desfazer o jogo do outro, ou seja, o espaço instituído por outros, caracterizam a atividade, sutil, tenaz, resistente, de grupos que (...) devem desembaraçar-se em uma rede de forças e de representações estabelecidas." (Certeau, 1998: 79)

No bojo de sua discussão sobre esses processos de invenção do cotidiano, Certeau (1998) trata a questão do espaço urbano e estabelece um paralelo entre a cidade criada por uma ordem dominante e a cidade habitada, recriada por meio das apropriações dos indivíduos, ou seja, por meio da prática do espaço. A primeira se manifesta na figura do voyeur, que "sai" do domínio do espaço e se coloca à distância e acima, em uma posição totalizadora que remete a uma espécie de ficção do saber, enquanto a segunda se revela na figura do praticante, que, no "interior" do espaço urbano, onde a visibilidade panorâmica cessa, caminha e 


\section{SÃO PAULO15 17 LISBOA $25 \sim 26$ JUN 2020

age a partir dos seus conhecimentos. Seguindo a perspectiva de Certeau para tratar das nossas cidades poderíamos dizer que enquanto a cidade criada pela ordem dominante está contida no modelo de operação da racionalidade ocidental, a cidade habitada é praticada, apropriada, modificada e criada com base em conhecimentos plurais que se manifestam cotidianamente e, ainda que não sejam lidos e decodificados pela perspectiva técnica e acadêmica, atualizam continuamente o espaço urbano e tecem as feições da vida social e cultural da cidade.

Estar atento à diversidade desses conhecimentos e saberes, segundo A. Escobar (2016), é uma postura que remete ao comprometimento do pensamento com a vida. Inserido no campo dos estudos decoloniais e interessado na construção de possibilidades de transformação social, o autor sustenta a ideia de que comprometer-se a retirar dos silenciamentos e invisibilidades a diversidade de saberes e experiências populares significa contribuir para a afirmação da coexistência de muitos mundos. É importante notar, no entanto, que alguns desses mundos só resistem e re-existem devido às lutas dos grupos sociais subalternizados, o que nos leva a compreender que a promoção do pluriverso - o mundo onde cabem muitos mundos - só é possível com a criação de pontes entre o conhecimento acadêmico e o social e entre a teoria e a prática. Para Escobar (2016), os saberes derivados das lutas em defesa dos territórios e da diversidade cultural são fundamentais e, inclusive, oferecem maior profundidade em relação aos saberes acadêmicos nos processos de transformação social. Nesse sentido, os conhecimentos e as práticas de sujeitos subalternizados e ativistas urbanos que se mobilizam em defesa de seus mundos constituem importantes fontes para os projetos de descolonização, resgate e emancipação dos mundos. Podemos dizer, ainda, que constituem importantes fontes para a reinterpretação dos saberes que produzem o espaço urbano e, consequentemente, para a reconstrução da história das cidades e a manutenção da sua memória. "Para revitalizar o pensamento crítico, é necessário aproximá-lo das ideias e práticas daqueles que lutam em sua defesa." (Escobar. 2016: 29, 30)

O entendimento do cotidiano enquanto âmbito dos conhecimentos plurais, das múltiplas veracidades, dos dissensos e das resistências em relação às ordens dominantes vem ao encontro, assim, da afirmação de Santos (2002) quando diz que algumas formas sociais e experiências, apesar de invisibilizadas e marginalizadas, nunca deixam de existir, são apenas mantidas sob a égide da desqualificação e do descrédito. Caberia à pesquisa histórica, portanto, nos termos da sociologia da ausência, revisitar essas experiências, práticas e lutas cotidianas, assim como os saberes populares, criativos e tradicionais que têm lugar em contextos considerados não existentes, e libertá-los "do seu estatuto de resíduo, restituindo-lhes a sua temporalidade própria e, assim, a possibilidade de desenvolvimento autônomo." (Santos, 2002: 251) Desobedecer às operações epistemológicas que produzem ausências significa defender o pluriverso urbano, ou seja, defender a existência de muitas cidades em uma. Afinal, segundo Santos (2002: 259), "Quanto mais ampla for a realidade credível, mais vasto é o campo dos sinais ou pistas credíveis e dos futuros possíveis e concretos."

\section{Breves considerações finais}

Em uma perspectiva de atualização dos estudos históricos sobre as cidades brasileiras no campo da Arquitetura e do Urbanismo, buscamos aqui refletir acerca de teorias que, dando continuidade aos esforços dos últimos trinta anos, possam contribuir na incorporação de novos debates e categorias de análise, no alargamento da perspectiva crítica, na inclusão de uma maior diversidade de sujeitos e na indicação de novas metodologias de pesquisa. Conforme apontado no início deste trabalho, temos hoje o desafio de 


\section{SÃO PAULO15 17 LISBOA $25 \sim 26$ JUN 2020

conjugar contribuições interdisciplinares e multiconceituais para que esses estudos históricos alcancem a complexidade e a densidade das múltiplas dimensões das cidades.

Tomando os estudos pós-coloniais e decoloniais como importantes contribuições teóricas para o movimento de aproximação da cidade real brasileira e dos seus múltiplos sujeitos - movimento este iniciado pela incorporação do debate da história social -, entendemos a necessidade de uma reconfiguração epistemológica que nos permita ler a nossa realidade urbana a partir de outras chaves de conhecimento comumente desqualificadas e descreditadas no âmbito acadêmico devido à histórica colonialidade do nosso saber. Acreditamos que os apontamentos sobre as práticas cotidianas e os saberes populares urbanos nos dão pistas nessa busca por novas leituras da cidade e novos métodos de pesquisa que deem conta de alcançar e pôr em diálogo os distintos e contraditórios processos, concretos e simbólicos, de produção e transformação dos espaços urbanos. Cabe imaginarmos, a partir dessas pistas, que tipos de fontes poderiam ser utilizadas para melhor decodificar o cotidiano urbano, suas práticas e seus saberes, já que muitos dos documentos frequentemente utilizados como fontes da pesquisa histórica são produzidos por atores hegemônicos da disciplina urbana.

É importante ressaltar, seguindo a historiadora S. Lara (2008), que, em geral, os documentos são produzidos para uma finalidade outra, que não a de fornecer informações sobre o passado. Isso significa dizer que é o pesquisador quem transforma tais documentos em fontes, o que reforça a sua responsabilidade de realizar uma boa seleção desse material. Para além disso, as afirmações de Lara nos lembram que é necessário inventar fontes, interrogá-las criticamente e compreendê-las no interior das circunstâncias e dos objetivos que envolveram a sua produção, a fim de alcançar as respostas pretendidas na investigação.

Nesse sentido e diante das reflexões aqui propostas, cabe-nos a atualização e a invenção dos nossos métodos e fontes a partir do quais lemos a cidade e construímos a sua história. Precisamos interseccionar campos de conhecimentos e imaginar que outros vestígios, para além dos documentos produzidos por técnicos e administradores públicos, poderiam nos revelar evidências e fragmentos dos múltiplos processos e saberes que envolvem a produção material e simbólica do espaço urbano. Os recentes debates entorno do conceito de história pública (Almeida; Rovai, 2011) - uma história que ultrapassa os muros da academia e estabelece pontes com os mais diversos grupos sociais - abrangem questões relativas às fontes da ciência histórica e inspiram algumas possibilidades para a construção de discursos alternativos aos hegemônicos por meio de fontes não escritas, uma vez que os documentos escritos tendem a ser fruto do mesmo padrão de racionalidade que já predomina no ambiente acadêmico. As fontes orais, por exemplo, têm o potencial de aproximar a pesquisa histórica de um método utilizado, tradicionalmente, para a transmissão de saberes e memórias, enquanto as fontes visuais produzidas por um olhar engajado podem amplificar práticas contrahegemônicas, contribuindo, assim, para reconfigurar os sentidos atribuídos aos espaços da cidade.

É fato que ainda precisamos empreender esforços para que mais sujeitos, práticas e saberes tenham voz e lugar em nossos estudos históricos sobre as cidades e para que possamos consolidar, no cerne destes, a compreensão da cidade como expressão dos diversos modos de viver e das distintas formas de criação, apropriação e transformação do espaço. Acumular uma pluralidade de conhecimentos ao nosso conhecimento acadêmico sobre as cidades e construir novos discursos históricos comprometidos com a diversidade das práticas e memórias urbanas parece ser um caminho promissor no sentido de preencher lacunas e corrigir falhas das escolhas teórico-práticas pautadas, prioritariamente, em visões totalitárias, tecnicistas, deterministas e homogêneas das cidades. Parece ser um caminho comprometido, portanto, não só com o passado das cidades, mas também com as possibilidades plurais para o seu futuro. 


\section{SÃO PAULO15 17 LISBOA $25 \sim 26$ JUN 2020}

\section{Referências bibliográficas}

ALMEIDA, J.; ROVAI, M. (2011). Introdução à história pública. São Paulo: Letra e Voz.

CARPINTÉRO, M.; CERASOLI, J. (2009). A cidade como história. Revista História: Questões \& Debates (Curitiba), n 50, 61-101.

CERTEAU, M. (1998). A invenção do cotidiano. Petrópolis: Editora Vozes.

ESCOBAR, A. (2016). Sentipensar con la Tierra: Las Luchas Territoriales y la Dimensión Ontológica de las Epistemologías del Sur. Revista de Antropología Iberoamericana, v 11, n 1, 11-32.

FARIA, R. (2015). História da Cidade, História do Urbanismo, História da Urbanização ou História Urbana? A interdisciplinaridade é o caminho para a pesquisa em Arquitetura e Urbanismo. Anais do 4 Seminário Nacional de Pesquisa e Pós-Graduação em Arquitetura e Urbanismo, São Paulo, 22-23 outubro (online).

FERNANDES, A.; GOMES, M. A. (2004). História da cidade e do urbanismo no Brasil: reflexões sobre a produção recente. Revista Ciência e Cultura (São Paulo), v 56, n 2, 23-35.

FONTANA, J. (1998). Reflexões do fim da história, do além do fim da história. In J. FONTANA. História: análise do passado e projeto social (267-281). Bauru: Edusc.

LARA, S. (2008). Os documentos textuais e as fontes do conhecimento histórico. Revista Anos 90 (Porto Alegre), v 15, n 28, 17-39.

LEFEBVRE, H. (2011). O direito à cidade. São Paulo: Centauro Editora.

SANTOS, B. S. (2002). Para uma sociologia das ausências e uma sociologia das emergências. Revista Crítica de Ciências Sociais (Coimbra), n 63, 237-280.

THOMPSON, E. P. (1981). Intervalo: A lógica histórica. In E. P. THOMPSON. A miséria da teoria ou um planetário de erros (47-62). Rio de Janeiro: Zahar Editores. 